\title{
IDENTIDADES NARRATIVAS E PERFORMATIVIDADE DE GÊNERO: CRUZAMENTOS CONCEITUAIS POSSIVEIS APÓS A MORTE DO SUJEITO
}

\section{Cássio Bruno de Araujo Rocha ${ }^{1}$}

Resumo: $\bigcirc$ artigo investiga cruzamentos conceituais possiveis entre as noções de identidade narrativa, conforme pensada por Ricoeur, Velleman e Maclntyre, e de performatividade de gênero, proposta por Butler, em meio à ambiência filosófica da crise (ou morte) do sujeito cartesiano na pós-modernidade. Este cruzamento tenta abrir um novo caminho para as escritas de histórias sobre os gêneros pautadas no seu fazer narrativo ao longo do tempo, entendendo os gêneros como construções culturais que se fazem por meio das ações e interpelações performáticas feitas pelos agentes e por eles sofridas - as quais são representadas pelo historiador através da narrativa que ele compõe.

Palavras-chave: identidade de gênero; identidade narrativa; performatividade de gênero.

\begin{abstract}
This paper investigates possible conceptual crossings between the notions of narrative identity, as thought of by Ricoeur, Velleman and Maclntyre, and gender performativity, proposed by Butler, in the midst of the philosophical ambience of the crisis (or death) of the cartesian subject in the postmodernity. This crossing is an attempt on openning a new way of writting gender's histories guided on its narrative making through time, understanding gender as cultural constructions that make themselves by the performativeactions and interpelations made by the agents and by them soffered - which are represented by the historion through the narrative that he composes.
\end{abstract}

Key-words: gender identity; narrative identity; gender performativity.

Este artigo objetiva analisar as possibilidades de cruzamentos entre os conceitos de identidades narrativas e de performatividade de gênero a partir do contexto teórico da suposta morte do sujeito moderno decretada pelas filosofias pós-modernas. Este cruzamento é uma tentativa de abrir um novo caminho para a escritas de histórias sobre os gêneros pautadas no seu fazer narrativo ao longo do tempo, entendendo os gêneros como construções que se fazem por meio das ações e interpelações performáticas feitas pelos agentes e por eles sofridas - as quais são representadas pelo historiador através da narrativa que ele compõe.

Parte-se da hipótese de que tal cruzamento é possivel devido à relação

1 Doutorando em História Social da Cultura no Programa de Pós-graduação em História da Universidade Federal de Minas Gerais. E-mail: caraujorocha@gmail.com. 
dialética que a identidade narrativa mantém com a teoria da ação, conforme sugerem Alasdair Maclntyre e Paul Ricoeur. Este último entende que a narrativa põe as ações em contato com sua dimensão ética (trazendo à baila a questão da responsabilidade de cada um por suas ações em um campo ético-moral) (RICOEUR, 2014, p.167). Deste modo, a hipótese inicial pode ser aprofundada pelo entendimento de que a narrativa composta pelo fazer-se performativo do gênero tem (ou deveria ter, se se pretende subversiva) como fio condutor ou princípio de coerência o cuidado de si para uma estética da existência - no sentido deste conceito apresentado por Michel Foucault.

Como foi dito, esta investigação insere-se no contexto filosófico dos debates acerca da categoria do sujeito. Entre o sujeito moderno e aquelas filosofias que - querem morto. Ou seja, em meio à crise do sujeito moderno. De modo que é preciso um desvio por essa ambiência para melhor entender as conexões da investigação aqui esboçada.

Em primeiro lugar, o que se entende, neste trabalho, por sujeito moderno é aquele consagrado inicialmente por Descartes com a célebre máxima do Cogito ergo sum. O filósofo francês instaurou uma revolução no pensamento ocidental, ao inverter a prioridade antes dada às coisas, e não à razão, na dinâmica do conhecimento. Descartes inaugura a filosofia moderna, ao tornar o sujeito o próprio fundamento do conhecimento, não só seu lugar. Sendo fundante, o sujeito pode dispor de todas as coisas no universo, tudo é seu objeto, não há nada que não seja uma representação de sua consciência (DESCARTES, 1973).

Birchal (2007) sintetiza algumas características principais do sujeito de Descartes. Segundo a filósofa, o sujeito mantém uma auto posição de si, tem certeza de si próprio - a sua existência é a única verdade que resiste ao poderoso método da dúvida cartesiana - consequentemente, o sujeito é a fundação de todo conhecimento. O sujeito é racional e puro pensamento (não tem corporeidade), é substancial (a coisa pensante segundo o Discurso do Método), universal, tem atividade (é o ato de pensar), é transparente a si mesmo, tem total liberdade e é nitidamente distinto de tudo que lhe é exterior (BIRCHAL, 2007, p. 16-18).

A revolução cartesiana marcou a transição de uma concepção antiga e medieval segundo a qual o ser humano ocupava um lugar desde já determinado na ordem cósmica ou divina para uma concepção moderna. Nesta, o homem tem uma centralidade ideal e é soberano sobre a totalidade do seu ser.

Descartes rejeitou inteiramente a noção de uma ordem cósmica que incorporaria as Ideias (segundo uma noção platônica), considerando-a um modo teleológico de pensar, abandonando toda teoria de ima razão ontológica. Para o filósofo francês, o universo deveria ser entendido mecanicamente pelo método científico proposto pioneiramente por Galileu. Esta mudança envolveu também uma mudança radical na antropologia, transformando o que se entende por 
virtude moral e domínio de si (TAYLOR, 1989, p. 143-158).

Assim, o sujeito em Descartes, um sujeito propriamente moderno, reina com sua razão desengajada e imanente a si. Para Descartes, não há uma ordem exterior de ideias para a qual o sujeito deve se virar em ordem de conhecer e usar sua razão. A percepção total da imaterialidade do ser, em Descartes, envolve perceber distintamente a fenda ontológica entre matéria e espírito (alma, ser pensante), o que envolve também perceber o mundo (a matéria) como mera extensão. A matéria inclui também o corpo, também uma extensão. Para atingir tal percepção, é necessário que o indivíduo se desengaje de sua perspectiva corporal usual. $\bigcirc$ mundo precisa ser objetificado pelo sujeito cognoscente, inclusive seu corpo, o que significa perceber toda a matéria (o mundo e o corpo) mecânica e funcionalmente, do mesmo modo que um observador externo faria (TAYLOR, 1989, p. 143-157).

Abriu-se caminho, dessa maneira, à dominação do mundo pela ciência e pela técnica. Com o iluminismo do século XVIII, o reino do sujeito expandiu-se para a moral e a política, a partir do que o homem se tomou como fundamento da construção da sociedade e da história.

Ao longo dos séculos, o sujeito moderno sofreu várias críticas, destacandose as efetuadas por Hume, Kant e Nietzsche (BIRCHAL, 2007, p. 19-20). Para o presente estudo, as críticas nietzschianas são mais importantes, porque alimentaram diretamente as filosofias da morte do sujeito que pulularam no ocidente a partir de meados do século XX.

Nietzsche se indispôs furiosamente com a modernidade, questionando profundamente a possibilidade de um sujeito como pensara Descartes. Contra a razão como fundamento do ser (o ser cartesiano é puro pensamento, é algo que pensa), Nietzsche prefere a vida, o instinto, a vontade de potência ${ }^{2}$. Na Genealogia da moral, ele revela as ilusões da linguagem que baseiam a razão e o sujeito, estes não são mais que invenções cujo objetivo é barrar o avanço da potência dos fortes sobre os fracos. O sujeito por trás das ações é inexistente, "Mas não existe um tal substrato; não existe 'ser' por trás do fazer, do atuar, do devir, 'o agente' é uma ficção acrescentada à ação - a ação é tudo" (NIETZSCHE, 2008, p. 33).

Nietzsche (2008) é furioso em seu ataque à metafísica, martelando-a em seus golpes contra a linguagem. Para ele, a linguagem nasce da expressão do poder dos senhores de dar nome às coisas, em uma forma de apropriação (NIETZSCHE, 2008, p. 17). Sendo a linguagem ilusória, o sujeito por trás da ação, em última instância, o cogito, é uma armadilha.

A partir da segunda metade do século XX, a crítica nietzschiana foi resgatada

2 Para Nietzsche (2008, p. 62), "(..) a essência da vida, a sua vontade de poder; com isso não se percebe a primazia fundamental das forças espontâneas, agressivas, expansivas, criadoras de novas formas, interpretações e direções, forças cuja ação necessariamente precede a 'adaptação'; com isto se nega, no próprio organismo, o papel dominante dos mais altos funcionários, aqueles nos quais a vontade de vida aparece ativa e conformadora" (grifos no original) 
por autores que, sob o signo da crise europeia-ocidental do pós-guerra, desconstruíram a modernidade. Dentro deste campo heterogêneo, destaco, as críticas de Michel Foucault e Judith Butler, que dizem respeito aos conceitos chave da investigação que aqui se empreende.

$O$ conceito de performatividade de gênero da filósofa Judith Butler descende da crítica nietzschiana da modernidade, sendo a Genealogia da Moral uma de suas fontes diretas. Salih (2012) ressalta a importância deste livro de Nietzsche para a teorização da identidade de gênero construída por Butler. Segundo Salih (2012), a afirmação nietzschiana de que "não existe 'ser' por trás do fazer, do atuar, do devir; o 'agente' é uma ficção acrescentada à ação - a ação é tudo", (NIETZSCHE, 2008 , p. 33) é o fundamento da ideia butleriana de que não há um sujeito ou um gênero ideais que constroem a identidade, a identidade de gênero é algo que se faz repetidamente, incessantemente, pelas ações e expressões que, à primeira vista, julgar-se-iam seus resultados (SALIH, 2012, p. 90).

Judith Butler questionou a existência de um sujeito universal e a priori das identidades de gênero - o que foi uma forma de teorizar as críticas feitas aos movimentos feminista e homossexual no periodo, questionando a validade do sujeito por eles pressuposto e que foi visto como uma representação de setores das classes médias brancas dos Estados Unidos (BUTLER, 2012, p. 17-24).

A partir da problematização do sujeito, a filósofa procedeu à desnaturalização das categorias de gênero e sexo, recolocando-as nas tramas dos discursos - e, derivando-se, da narrativa. Retomando a questão de por quais modos a identidade, sobretudo a de gênero/sexual, é construída no e pelo discurso (na narrativa também?), Butler postula um sujeito como sempre em processo, que se constrói no discurso pelos atos que executa ou performatiza. Assim, a identidade de gênero é reconceituada no âmbito da performatividade como uma sequência de atos sem ator ou autor preexistente. A identidade, por exemplo, de mulher, é um devir, um construir sem origem ou fim. A identidade, portanto, está aberta a certas formas de intervenção e de ressignificação contínuas, porquanto seja uma prática discursiva (BUTLER, 2012, p. 26-33).

A teorização do gênero e do sexo em Butler é uma forma de combater a chamada metafísica da substância, isto é, a crença difundida de que o sexo e o corpo são entidades materiais naturais e auto evidentes. A filósofa argumenta, ao contrário, que o gênero não é natural e que não há uma relação necessária entre o corpo de alguém e o seu gênero. Todavia, ela também alerta que, mesmo não sendo natural, o gênero pode se apresentar como se o fosse, nos casos em que se cristaliza (BUTLER, 2012, p. 37-49).

$\bigcirc$ conceito de performatividade de gênero permite pensar o gênero, 0 sexo e o desejo para além das amarras da heterossexualidade compulsória e dos processos de naturalização, corporificação e interiorização dos gêneros e de suas 
hierarquias. Os atos que compõem o gênero são performativos pois a essência ou identidade que pretendem expressar são construtos, feitos e embasados por signos corpóreos e outros meios discursivos que interpelam o sujeito do gênero a seguir determinada ordem. Sendo um efeito de atos performativos em permanente e corriqueira repetição, o gênero não é uma instância original e interior ou uma categoria a ser atingida, antes é uma cópia destinada ao fracasso.

Uma vez que o sexo e o gênero podem apresentar-se como naturais, a tarefa de desfazer esse artifício das próprias relações que os constituem torna-se mais importante. Butler (2012) procura fazê-lo por meio do que ela chama uma genealogia da ontologia de gênero ${ }^{3}$, em que ela investiga o sujeito como efeito das relações de poder. As identidades de gênero e de sexo acontecem no interior da lei, sendo por ela conformadas. Observe-se que Butler (2012) trabalha com a analítica foucaultiana do poder, ou seja, como múltiplo, proliferativo e potencialmente subversivo a si mesmo. A liberdade de escolha individual no que concerne ao gênero e ao sexo é limitada, porém existe. A filósofa expõe essa liberdade como a possibilidade de interpretar as normas existentes de gênero, organizando-as de uma nova forma. Entendido dessa maneira, o gênero é um projeto tácito para renovar a história cultural do indivíduo segundo seus próprios termos; uma tarefa na qual ele está empenhado desde sempre. Porém, sempre com as limitações impostas pelos dispositivos discursivos de poder, uma vez que a filósofa postula que não há posição de liberdade para além do discurso. É no espaço dessa renovação ou subversão possivel, que este texto escreve o problema do gênero na dimensão narrativa por meio da noção de cuidado de si.

Faz-se necessário, neste momento, uma pausa para precisar o conceito de cuidado de si. Foucault voltou-se para este conceito ao analisar os modos como o pensamento grego e romano antigo abordou a prática sexual como um problema ético e moral. A leitura de textos gregos e latinos antigos impôs-se a Foucault como um desdobramento necessário de seu trabalho de pesquisa acerca de sua problemática tradicional, que era saber como o sujeito humano participava dos jogos de verdade (FOUCAUT, 2012, p. 258). Em suas pesquisas sobre a sexualidade (no sentido específico de regime de verdade implicado em relações de poder-saber e em modos particulares de sujetificação), o filósofo abordou os diversos modos pelos quais os indivíduos foram levados a dar sentido e valor à conduta. $O$ primeiro volume da História da Sexualidade expôs alguns mecanismos através dos quais os indivíduos foram (e são) levados a experimentar sua vida sexual como a parte mais importante de sua constituição como sujeito em articulação

3 A genealogia em Judith Butler deve ser entendida no sentido foucaultiano, conforme expresso no artigo "Nietzsche, a genealogia e a história" do filósofo francês: "Fazer a genealogia dos valores, da moral, do ascetismo, do conhecimento não será, portanto, partir em busca de sua 'origem', negligenciando comoinacessiveis todos os episódios da história, será, ao contrário, se demorar nas meticulosidades e nos acasos dos começos, prestar uma atenção escrupulosa à sua derrisória maldade; esperar vê-los surgir, máscaras enfim retiradas, com o rosto do outro; não ter pudor de ir procurá-las lá onde elas estão, escavando os bas-fond; deixar-lhes o tempo de elevar-se do labirinto onde nenhuma verdade as manteve jamais sob sua guarda". (FOUCAULT, 1979, p. 19). 
com um sistema de regras e coerções. Nesse conjunto, estão correlacionados, em uma cultura, campos do saber, formas de normatividade e de subjetividade (FOUCAULT, 1984, p. 10).

Ao preparar a continuidade da história da sexualidade, Foucault considerou que deveria abordar três eixos constitutivos da sexualidade. São eles a formação dos saberes que se referem a ela, os sistemas de poder que controlam sua prática e as maneiras dos indivíduos se reconhecerem como sujeitos dessa sexualidade. Para tratar dos dois primeiros eixos, seus estudos anteriores sobre a psiquiatria e a medicina ${ }^{4}$ e sobre os poderes punitivos e as práticas disciplinares ${ }^{5}$ forneceram-lhe instrumentos de análise. Foi a abordagem do terceiro eixo que impôs a necessidade de retornar aos textos clássicos, como forma de realizar uma história da hermenêutica de si, dos modos como, através dos tempos, os homens interrogaram seus desejos, procurando se reconhecer como sujeitos de desejo (FOUCAULT, 1984, p. 11-13). Para fazer isso, Foucault entendeu ser necessário retomar os textos da Antiguidade para fazer uma genealogia dos modos de subjetivação que, progressivamente, construíram os sujeitos humanos como hermeneutas de seus desejos em meio a diferentes regimes de verdade do sexo (como o da carne cristã e o da sexualidade moderna).

O cuidado de si é então o trabalho que cada um deve exercer em sua vida para torná-la esteticamente aprazivel, boa e honrada, enfim, para constituir uma estética da existência. $O$ conceito de estética da existência aparece na obra de Foucault como o modo pelo qual filósofos, moralistas e médicos da Antiguidade greco-romana constituíram a vivência sexual como um problema moral, ético e político. Certos aspectos da prática sexual tornaram-se problemáticos para gregos e romanos na medida em que se considerou que apresentavam, no seu uso cotidiano, desafios à liberdade dos homens. Essa problematização, contudo, não tomou a forma de um código universal de regras e proibições sobre o sexo (como viria a ser sob o cristianismo). $O$ trabalho que cada um deveria exercer sobre si, o cuidado que deveriam tomar consigo mesmos, era baseado em princípios gerais de conduta existentes na cultura clássica que apontavam para os modos de um uso moral dos prazeres.

A sujetificação moral do indivíduo não passava, na Antiguidade greco-romana, pela obediência a um código universal ou mesmo por regras detalhadas de quais atos fazer ou não (não passava por um sistema jurídico). Essa construção era uma estilização da existência, pois consistia na observação e na prática dos desejos estritamente conforme a natureza ao longo das relações de si com os outros e, principalmente, consigo mesmo. $\bigcirc$ importante na Antiguidade clássica não era especificar como levar a vida sexual, mas como conduzir a vida em relação

4 Estes trabalhos são, sobretudo, os da fase arqueológica do filósofo. Trata-se das obras História da Loucura, O Nascimento da clínica (FOUCAULT, 2012b) (FOUCAULT, 1977).

Estes são os trabalhos da fase genealógica do autor. Os maiores destaques são Vigiar e punir e História da Sexualidade I: a vontade de saber (FOUCAULT, 2011) (FOUCAULT, 1977b). 
a si em uma postura viril perante os prazeres. Uma vida conduzida - estilizada, construída, transformada - de tal maneira seria uma existência temperante, logo, de acordo com a natureza, logo, boa e bela.

Vê-se que a estética da existência era uma prática ética ${ }^{6}$ da liberdade do cidadão da pólis. Por essa razão, importou ao pensamento greco-romano aplicar essa estilização da conduta às principais dimensões da vida do homem livre adulto. Tais dimensões foram o cuidado com o próprio corpo (uma dietética), o cuidado com o oikos, a casa em sentido amplo, e com a relação conjugal com a mulher (uma econômica) e o cuidado com o amor aos rapazes (uma erótica) - cujo desenvolvimento poderia desembocar no verdadeiro amor, e o ápice do cuidado de si, que era o amor à verdade e ao conhecimento em si. A estética da existência é definida, pois, por Foucault como "a arte refletida de uma liberdade percebida como jogo de poder" (FOUCAULT, 1984, p. 317).

cuidado de si visando uma estética da existência é uma das respostas cogitadas por Judith Butler ao problema da linguagem em meio à redefinição da identidade de gênero em termos discursivos. Nas palavras da autora, "então que linguagem resta para compreender essa representação corporal, esse gênero, que constitui sua significação "interna" em sua superficie?" (BUTLER, 2012, p. 198). Entre as respostas sugeridas pela autora, está a estilistica da existência de Foucault.

Destarte, o conceito de estética (ou estilística) da existência do filósofo francês pode contribuir para a percepção da performatividade em que $\circ$ gênero é construído. Ou, a performatividade do gênero pode esclarecer os modos pelos quais a existência é construída esteticamente pelos indivíduos na contemporaneidade. Neste texto, pretende-se dar um passo ainda além, interrogando-se os aspectos narrativos da identidade assim definida. Guardadas as distâncias devidas aos diferentes contextos de elaboração dos conceitos, a articulação dos mesmos ajuda a pensar novos modos de abordagem à história dos gêneros, compreendendo formas de atuação e resistência das personagens históricas para além da temática da liberação e da posição de vitimização de certos grupos.

Ainda que Foucault negasse fazer uma filosofia prescritiva de modos de viver ou de agir ética e politicamente ${ }^{7}$, seu pensamento propõe questionamentos importantes para a cultura contemporânea marcada pela globalização dos mercados, das informações e das pessoas em um capitalismo sem quaisquer fronteiras. $\bigcirc$ autor ressaltou que, em um mundo no qual $\circ$ imperativo de

\footnotetext{
6 Segundo Foucault, deve-se entender ético nesse contexto "no sentido que os gregos podiam entendê-lo: o êthos era a maneira de ser e a maneira de se conduzir. Era um modo de ser do sujeito e uma certa maneira de fazer, visivel para os outros". (FOUCAULT, 2012, p. 264).

$7 \quad$ "De forma alguma faço isso para dizer "infelizmente, esquecemos o cuidado de si; pois bem, o cuidado de si é a chave de tudo". Nada é mais estranho para mim do que a ideia de que a filosofia se desviou em um dado momento e esqueceu alguma coisa e que existe em algum lugar de sua história um princípio, um fundamento que seria preciso redescobrir. (...) $\bigcirc$ que, entretanto, não significa que o contato com esta ou aquela filosofia não possa produzir alguma coisa, mas seria preciso enfatizar que essa coisa é nova". (FOUCAULT, 2012, p. 273-274)
} 
uma estrita obediência a um código moral universal se desvanece, aumenta a importância de uma busca por uma estética da existência. Sendo essa também uma razão para seu desvio pelas morais da Antiguidade greco-romana (FOUCALT, 2012, p. 283).

A performatividade do gênero foi elaborada por Judith Butler como o modo de explicar o processo de construção histórico-cultural dos gêneros dentro dos sistemas do binarismo sexual-generificado e da heterossexualidade compulsória. Essa construção ocorre nos termos da analíticafoucaultiana do poder, logo, dentro de uma compreensão dos poderes como positivos, isto é, múltiplos, relacionais e proliferativos. De modo que, mesmo sendo uma construção compulsória, a performatividade pode ser apropriada e transformada pelos sujeitos dentro dos limites das relações discursivas de poder.

Butler ((2012) trabalha essa apropriação possivel como o lugar de possibilidade da subversão das hierarquias de gênero e da heterossexualidade compulsória. Nos termos de Foucault, a subversão pode ser pensada como as resistências estratégicas aos modos de sujeição que acompanham os processos de sujetificação nas sociedades modernas. Resistências que, como práticas de liberdade, são também formas de cuidado de si para a elaboração de uma estética da existência.

Segundo Veyne (2009), o conceito de cuidado de si explicita os modos mais livres pelos quais o sujeito pode se constituir dentro do pensamento de Foucault. É preciso ressaltar que Foucault não destruiu o sujeito na história, apenas o deslocou e o colocou na contingência própria da história. $\bigcirc$ sujeito que existe nas narrativas do filósofo é modelado em cada contexto pelo discurso e pelo dispositivo então vigentes, mas também "pelas reações da sua liberdade individual e pelas suas eventuais estetizações" (VEYNE, 2009, p. 109). Dessa maneira, o sujeito, mesmo em Foucault ou em Butler, tem abertura suficiente para que possa ser pensado também em termos narrativos, considerando-se que é na e através da narrativa que ele se constitui em suas contingências históricas e culturais.

É importante agora examinar quais relações a identidade narrativa pode manter com uma identidade de gênero construída performativamente com vistas a um cuidado de si para uma estética da existência. Um ponto inicial de ligação é o fato de a identidade de gênero ser aqui pensada como construída através das (e nas) ações do sujeito. Segundo Ricoeur (2014), há uma proximidade entre as ações praticadas por alguém (pelo sujeito, ou, nos dizeres do autor, pelo simesmo) e a dimensão narrativa da identidade.

Conforme o autor, há uma correlação entre ação e personagem na narrativa. Essa correlação ou conexão é constituída pela composição do enredo narrado, o que integra o descontínuo da vida na permanência do tempo que se narra. Esta propriedade integradora do enredo é denominada configuração narrativa pelo 
autor (RICOEUR, 2014, p. 147), e diz respeito à composição entre o princípio da ordem da organização dos fatos (exigência de concordância) e os reveses que transformam, de modo regrado, o enredo do seu começo até o seu fim (admissão de discordâncias). Os acontecimentos assim compostos têm um status particular, são acontecimentos narrativos, o que significa que são tanto fontes de discordância (quando surgem inesperadamente), quanto de concordância (quando avançam a narrativa) (RICOEUR, 2014, p. 148).

Ricoeur (2014) avança ainda, afirmando o sujeito narrativo como a personagem que executa a ação na narrativa. Porém, o sujeito-personagem não é uma reedição da figura do sujeito como aquele que preexiste à ação, o sujeito-personagem é composta em enredo, por ter uma identidade correlativa à própria história narrada (RICOEUR, 2014, p. 149). Assim, vê-se que colocar a identidade na narrativa responde às perguntas que se faz a uma ação, ou seja, na narrativa, estão respondidas as questões de quem fez o quê, por quê fez e como fez. Ainda mais, na narrativa, as respostas a essas perguntas estão estendidas no tempo (RICOEUR, 2014, p. 153). Narrar, portanto, é estender no tempo as circunstâncias da ação.

Retornando à identidade de gênero, vê-se que ela também pode ser colocada em termos narrativos a partir da conexão explicada por Ricoeur (2014) entre ação e narrar. Butler (2012), viu-se, mostra que o gênero se faz nos atos, ele não existe de antemão. Tais atos são também ações - como escolher uma roupa identificada a este ou aquele sexo (aqui em sentido comum), chamar-se por determinado nome, ou responder quando por ele chamado, praticar determinado ofício, etc. - e, como tais, encadeiam-se à narrativa como acontecimentos que compõe o enredo e, através dele, a personagem. Da mesma forma como não há um sujeito anterior ao gênero, igualmente não há um sujeito-personagem anterior à narrativa. $O$ gênero se faz em processo, bem como a identidade narrativa.

Narrar a construção da identidade de gênero, então, é jogar as ações que o sujeito exerce e padece (seguindo o vocabulário de Ricoeur) ${ }^{8}$ no terreno narrativo, - que pode trazer contribuições para a historiografia do gênero. A identidade de gênero comporta, como já foi visto, certo nível de agência do sujeito em sua performatividade, contudo, ela é principalmente constrangida por uma cadeia de citacionalidade que atualiza sempre as hierarquias culturais de gênero.

A repetição performativa que constitui o gênero é redefinida agora como uma cadeia de citações das práticas e discursos autoritários. A cada ato performativo repetido, em cada injúria (sofrer, padecer, o ato de ser chamado, por exemplo, de veado, sapatão) que reposiciona os sujeitos nos quadros de práticas punitivas, toda a experiência anterior de definição do gênero é trazida de volta ao presente na forma da citação. Desse modo, o conceito de citação apropriado por Butler de Derrida retira a

8 A mediação entre o narrar e o descrever, entre a narrativa e a ação, aproxima o sujeito da ação ao conceito de homem agente e padecente. (RICOEUR, 2014, p. XXXIII). 
categoria de intencionalidade de sua posição dominante nas cenas de construção dos gêneros. $A$ intencionalidade ainda pode existir, mas somente nos limites da cadeia citacional (DERRIDA, 1991, p. 349-373) (BUTLER, 1993, 223-241).

Dessa maneira, o gênero é performativo na medida em que é o efeito de um sistema regulatório das diferenças de gênero em que eles são divididos e hierarquizados de modo constrito. A performatividade de gênero, portanto, é a reiteração ou a repetição, por meio de cadeias citacionais, de normas de gênero que constituem cada um. Ela é a compulsória repetição de normas sujetificantes anteriores (citadas), normas que não podem ser desprezadas conforme as vontades individuais. Tais normas constroem, animam e limitam o sujeito generificado.

A cadeia citacional que engendra o fazer performativo do gênero pode ser aproximada ao conceito de cenário em Maclntyre - a ambiência em que a narrativa se dá. Maclntyre mostra que as ações, o comportamento, devem ser pensadas em relação às intenções de quem as exerce, e estas intenções somente têm sentido em contextos determinados que as tornam inteligiveis - seja aos próprios agentes, seja aos demais. $\bigcirc$ autor entende cenário em sentido social (uma instituição, uma prática, etc.), um tipo de organização humana que tem uma história que consiga conter inúmeras outras histórias de agentes, situandoas na passagem do tempo. $O$ cenário é aquilo que dá inteligibilidade às ações deparadas com o fluir do tempo (MACINTYRE, 2001, p. 347).

Vale destacar aqui o modo como Maclntyre (2001) compreende a mediação entre ação e narrativa dentro de um cenário social, para efetuar um cruzamento mais profundo com o problema da identidade de gênero. Para o filósofo, a ação que se presta à narrativa (na verdade, aquela sobre a qual cabe pensar sobre) é a ação inteligivel, pois dela pode-se dizer que é de responsabilidade de determinado agente. A ação inteligivel flui de intenções e propósitos de um agente humano, ao qual pode-se pedir uma explicação sobre seu ato. Estas intenções por trás da ação têm sentido em determinados contextos, dentre os quais o autor destaca a conversa como aquele que dá inteligibilidade aos atos de fala que dizem as ações (MACINTYRE, 2001, p. 351-355).

A conversa é um contexto especialmente importante, segundo Maclntyre, também porque serve de modelo às demais interações humanas, as quais são todas narrativas encenadas. A narrativa, para o autor, é o meio pelo qual o sujeito entende a vida que vivencia - o sujeito entende o que vivencia em modo narrativo. Isso acontece porque os atos têm caráter histórico, o que faz com que a narrativa seja o modo mais adequado para entender os atos de outrem - bem como os do próprio sujeito (MACITYRE, 2001, p. 355-356).

Retornando à identidade de gênero, agora no contexto narrativo de Maclntyre (2001), pode-se pensar nos atos que engendram o gênero de modo performativo como partes de uma narrativa que encena a constituição (nunca terminada) do 
gênero. As ações que vão constituindo o gênero, da mesma forma que aquelas previstas por Maclntyre (2001), só têm sentido em contextos determinados - o que explica a multiplicidade de identidades de gênero existentes, mesmo em uma só cultura. $\bigcirc$ gênero, portanto, encena-se dentro de contextos específicos - e esta encenação pode ser uma repetição tediosa das hierarquias estabelecidas ou uma audaciosa subversão que pretende estilizar a existência, ou a narrativa.

Os cruzamentos até agora feitos entre os conceitos demandam um aprofundamento na noção de identidade narrativa. Esta, todavia, não tem uma definição univoca. Para os fins deste texto, serão trabalhadas as considerações de Paul Ricoeur, A. Maclntyre e J. David Velleman a respeito do conceito.

O conceito de identidade narrativa tem sido desenvolvido por alguns filósofos como uma via possivel para solucionar o impasse entre a adesão ao sujeito moderno cartesiano ou a sua rejeição completa. A identidade narrativa aparece neste cenário como uma alternativa entre a unidade e a fragmentação do sujeito.

A identidade narrativa recoloca o sujeito em uma construção processual de si, a qual se faz pela e na narrativa. Assim, está anulada a pressuposição de um Eu substancial. A construção da identidade se faz pela ação hermenêutica das pessoas sobre as suas experiências a partir de relações causais e de um certo telos ou de um horizonte de expectativas. $O$ sujeito da identidade narrativa incorpora em si as representações narrativas de suas ações, de modo que elas compõem sua subjetividade, na medida em que esta acontece no realizar de tais ações, de modo que ele, dentro do contexto das determinações que o constrangem, assume por elas responsabilidades - com as implicações éticas deste fato.

Velleman (2006) aborda a identidade narrativa dentro de uma problematização da existência ou não de um Self. $O$ filósofo quer demonstrar que os seres humanos, ao mesmo tempo, inventam certa forma do Self e são certa forma do Self. Porém, tais formas não são as mesmas (VELLEMAN, 2006, p. 206). O Self inventado é a imagem de si que individualiza a concepção de si de todos, e - Self que existe desde antes é a capacidade para entender os comportamentos de cada um à luz da concepção que cada um inventa sobre si mesmo. $O$ tipo factual do Self diz respeito à agência autônoma, isto é, à faculdade do agente de traçar um entendimento causal para seu comportamento. Em termos narrativos, Velleman argumenta que a imagem de si que individualiza nossa concepção de nós mesmos corresponde ao protagonista da autobiografia composta pelos seres humanos, enquanto a capacidade que a pessoa tem para o entendimento causal é a capacidade que se tem para urdir uma narrativa coerente a partir das experiências de sua vida. É o ser como narrador (VELLEMAN, 2006, p. 7-8).

A teoria de Velleman (2006) sobre a subjetividade pode ser assim resumida: - Self é o narrador, a porção ou propriedade interna a cada pessoa que efetua o narrar. Este ato acontece de forma tal que, ao fazê-lo, o Self-narrador decide, 
segundo razões de contexto, suas próximas ações no mesmo passo que as articula à narrativa. De acordo com Velleman (2006), a narrativa autobiográfica e o comportamento (as experiências) que ela narra são mutuamente determinantes. O Self fictício criado pela narrativa não é só uma abstração útil para a interpretação das experiências que são representadas na narrativa; até certa extensão, o Self fictício determina as experiências do sujeito. $\bigcirc$ Self narrativo comporta-se segundo aquilo que faz mais sentido segundo seus desejos e crenças (seu contexto ou cenário), o que é uma razão anterior, mais básica do que seu próprio condicionamento a fazer o que fará mais sentido ao ser representado na narrativa (VELLEMAN, 2006, p. 211-220).

De sua teoria da subjetividade, Velleman (2006) conclui que na medida em que a pessoa tem em si um agente unificado, ela tem um Ser na forma de um locus interno de controle agencial. Este locus interno de controle agencial é o Narrador Interno (que narra ações desempenhadas segundo motivos, elaborando-os na narrativa), e ele nos torna unificados ao tomar decisões com base em razões. Uma segunda conclusão, é que o protagonista da autobiografia é ao mesmo tempo fictício e factual. É fictício porque seu papel (suas ações) é inventado por quem o desempenha. É factual porque este papel (estas ações) é de alguém inventando e desempenhando simultaneamente este papel. $O$ autor da autobiografia é idêntico ao protagonista da narrativa, na medida em que o protagonista é retratado como um personagem que improvisa a si mesmo, como autor-ator de sua própria história - o que o torna um agente autônomo. Finalmente, o autor conclui que - que torna o narrador interno um agente unificado é sua propriedade de ter uma unidade agencial - O Selfé o Self em diferentes narrativas de si porque ele integralmente narrou e desempenhou cada ação segundo motivos específicos de contexto em cada momento. A unidade do Self, para Velleman, finalmente, não é a unidade temporal de uma identidade pessoal, mas sua característica de agente autônomo - uma a parência específica do Self (VELLEMAN, 2006, p. 221-223).

Maclntyre (2001) afasta-se da conceituação de Velleman (2006) ao não problematizar a questão da ficcionalidade ou da factualidade da subjetividade narrativa. Para ele, como para Ricoeur (2014), este é um problema da linguagem em mediação com a ação e com a ética. Para Maclntyre, há uma mediação possivel entre ações e narrativa porque o homem é um ser contador de histórias - e, ao longo do tempo, essas histórias passaram a aspirar à verdade. Ao menos o discurso historiográfico tem essa aspiração. A história é definida pelo autor, consequentemente, como uma narrativa dramática (apenas dramática?) encenada, nela as personagens são também autoras. É certo que nenhuma personagem na história aparece na narrativa do seu começo (ou de sua origem), e tampouco qualquer um verá seu fim. Ademais, nenhuma pode se conduzir na narrativa de modo absolutamente livre. No entanto, e isso diferencia personagens históricas reais de personagens fictícias, as primeiras têm certo nivel de autoria 
- ou de agência. As restrições a essa agência são dadas pelas ações das demais personagens-autoras e pelos cenários sociais que dão inteligibilidade às ações de todas (MACINTYRE, 2001, p. 361-363).

As narrativas vividas (a identidade narrativa, pode-se dizer) é caracterizada, segundo Maclntyre (2001), por um caráter ao mesmo tempo imprevisivel e (parcialmente) teleológico. São imprevisiveis porque não são regidas por leis universais, e teleológicas, até certo ponto, porque são moldadas por certa expectativa de futuro - certo horizonte de expectativas que molda as ações das personagens-autoras.

Como já foi mencionado, para Maclntyre (2001), a narratividade das ações está vinculada à noção da responsabilidade dos sujeitos por elas. $\bigcirc$ autor afirma que sem a responsabilidade do Eu (dada por sua unidade exigida pela narrativa), não há continuidade possivel do contexto, logo, não há o que dê inteligibilidade a suas ações e às narrativas assim construídas. De modo que a unidade do sujeito é dada por um jogo de pressuposições mútuas entre os conceitos de narrativa, inteligibilidade, responsabilidade e identidade pessoal. Pressupostos assim dinamicamente, os quatro conceitos conformam a unidade de uma vida individual que é a unidade do sujeito em uma narrativa que expressa sua (única) vida (MACINTYRE, 2001, p. 365-367).

A partir da noção de unidade de uma vida humana, Maclntyre (2001) conecta a identidade narrativa à busca ética por uma boa vida. Uma busca que é narrativa. A busca é entendida pelo autor como um conceito parcialmente teleológico e voltado para o conhecimento de si. É parcialmente teleológica porque busca-se um fim, que é o bem. A procura pelo bem tem o poder de lapidar a concepção do sujeito a respeito do bem, de modo que seu fim vai sendo discernivel durante sua execução. E essa progressão é uma jornada por um maior conhecimento de si. $\bigcirc$ autor concluí então que a vida virtuosa para o homem é aquela levada em busca da vida boa para o homem (MACINTYRE, 2001, p. 368-369). Essa conclusão merece ser confrontada com a noção de cuidado de si que orienta uma vivência subversiva da identidade performativa de gênero - conforme visto anteriormente.

O autor não encerra aí sua interrogação sobre a conexão entre a identidade narrativa e a ética. Para ele, é a ideia de tradição que comporta essa conexão. Tradição entendida por ele como algo vivo que comporta continuidades de conflitos narrativos, "uma argumentação que se estende na história e é socialmente incorporada" (MACINTYRE, 2001, p. 373). A tradição compõe a identidade pessoal de cada sujeito, pois a história de sua comunidade e a sua história de vida individual contêm-se mutualmente. Com isso, o autor quer dizer que a história em que cada um é personagem e coautor está inserida em histórias mais antigas e gerais das tradições que o rodeiam e o preenchem (MACINTYRE, 2001, p. 373-374). 
Não se entenda que o autor seja partidário de um conservadorismo político e ético, pois sua noção de tradição está embebida na narrativa, ou seja, o que ele entende por tradição é uma narrativa mais ampla que aquela das personagens individuais e que as conecta com outras instâncias temporais, na medida em que o prosseguimento da narrativa é vivenciado como uma expectativa de futuro informada por um espaço de experiência passado.

Não obstante isso, há que se pensar o entendimento de Maclntyre (2001) sobre a unidade (narrativa) de uma vida individual virtuosa (voltada ao conhecimento de si) em relação à noção aqui proposta do cuidado de si como modo de vivenciar (também narrativamente) a identidade de gênero. Está em jogo aqui a dualidade lembrada por Foucault na Hermenêutica do sujeito entre as fórmulas gregas do "conhece-te a ti mesmo" e do cuidado de si. Foucault problematiza a razão pela qual à primeira foi dada uma importância muito maior que à segunda na história da filosofia. Ao "conhece-te a ti mesmo" foi primeiramente colocada a questão do sujeito e da verdade, sendo o cuidado de si uma noção marginal (FOUCAULT, 2010, p. 4-5).

Logo de saída, Foucault (2010) observa como os significados históricos do "conhece-te a ti mesmo" (inscrito à entrada do templo de Apolo em Delfos) são incertos ${ }^{9}$, mas, para ele, isto é o menos importante. O que é de consequência é o contexto da introdução da máxima na filosofia. E esse contexto gira em torno da figura de Sócrates nos textos de Platão e de Xenofante. Mais importante ainda, Foucault considera que o "conhece-te a ti mesmo" aparece acoplado à noção de cuidado de si, seria a forma mais exemplar de uma vida levada com cuidado para consigo mesmo com vistas a uma estilistica da existência (FOUCAULT, 2010, p. 6).

Tomando o reposicionamento da busca por autoconhecimento feita por Foucault, a preocupação ética da identidade narrativa em Maclntyre (2001) se revela também como uma forma do indivíduo-personagem-coautor traçar o enredo de sua própria narrativa tendo sempre uma preocupação estéticaética com sua existência. A identidade de gênero, cujos atos performativos podem ser colocados em narrativas, pode também ser entendida como uma busca pela boa vida, se, por boa vida, entender-se um jogo com as narrativas das tradições em que aquelas pouco virtuosas (isto é, as que reificam as hierarquias opressoras de gênero e sexualidade) são subvertidas em nome de um fortalecimento das tradições mais virtuosas (aquelas que abrem espaço para vivências autônomas do gênero e da sexualidade).

Resta agora considerar o que Ricoeur (2014) entende por identidade narrativa. $O$ autor aborda a identidade narrativa como modo de solucionar, ou ao menos tornar produtivas, as aporias da identidade pessoal. O que é possivel, porque a narrativa resgata a dimensão temporal da existência humana. Ricoeur explica a 
identidade narrativa como a dialética temporal entre duas formas de identidade, a identidade no sentido de idem e no sentido de ipse. A primeira (a mesmidade) diz daquilo na identidade que permanece no tempo, que é contrário ao mutável, sendo o que torna o sujeito um ente social. A segunda (a ipseidade) diz daquilo na identidade que muda de um individuo a outro, sua especificidade que decorre da narrativização de sua vida e das promessas que ele faz (RICOEUR, 2014, p. XIII-XIV).

É preciso, pois, pensar as duas formas de identidade propostas por Ricoeur (2014) dentro da permanência no tempo. A identidade como mesmidade envolve alguns critérios para a definição do si como si mesmo. $O$ primeiro é o de identidade numérica, segundo o qual duas ocorrências de uma coisa com o mesmo nome não dizem de duas coisas, mas de uma coisa só - é um critério para reconhecer o mesmo inúmeras vezes. O segundo critério é o da identidade qualitativa, que permite reconhecer uma coisa como si mesma devido a uma extrema semelhança. A passagem do tempo pode instaurar a dúvida entre estes critérios, de modo que se usa um terceiro, o da continuidade ininterrupta da coisa ao longo do tempo - capaz de fortalecer o critério de identidade qualitativa. Este critério diz da continuidade ininterrupta entre o primeiro e o último estágio de desenvolvimento do que se considera um mesmo e único indivíduo. O critério final da definição do si-mesmo ao longo do tempo (sua identidadeidem) é o princípio da permanência no tempo de uma estrutura invariável da coisa (RICOEUR, 2014, p. 115-117).

A ipseidade também deve ser pensada na dimensão temporal, para que a dialética com a mesmidade abra espaço para a solução narrativa da identidade pessoal. A identidade-ipse (aquilo no indivíduo que o especifica) permanece no tempo de duas formas, uma pela constância do caráter, outra pelo cumprimento da promessa feita, pelo resgate da palavra empenhada. Por caráter, Ricoeur (2014) entende o conjunto de marcas distintivas que permitem sempre identificar o indivíduo como o mesmo ao longo do tempo, as suas disposições por cuja durabilidade, por sua persistência como hábito, são capazes de identificar a pessoa. Este hábito das disposições que formam o caráter confere a este uma história, que diz de uma mudança (o momento em que se contrai o hábito) e de uma permanência (a sedimentação do hábito no caráter). Mais ainda, as disposições que formam o caráter relacionam-se também com o outro, são uma forma de entrada do outro no si-mesmo. Uma pessoa reconhece-se nos modelos culturais de uma comunidade (da sua comunidade) e passa a se identificar, em seu caráter, por eles. Vê-se que, pela permanência do caráter no tempo, a ipseidade e a mesmidade se aproximam e se confundem (RICOEUR, 2014, p. 118-122).

segundo modo da ipseidade permanecer no tempo - o cumprimento da palavra dada - afasta-se da mesmidade, dissociando-as. $\bigcirc$ cumprimento da promessa é um modo de permanência no tempo específico e diz unicamente do questionamento sobre quem realizou a promessa, fazendo com que a 
conservação do si não coincida com a da sua identidade-idem. Cumprir a promessa feita é simultaneamente negar a mudança e desafiar o tempo que a impinge, porque a justificativa ética que garante o cumprimento da promessa - faz a despeito das mudanças nas disposições iniciais do caráter do Eu que prometeu. Assim, ao opor a ipseidade e a mesmidade por meio de um modo novo de permanência no tempo (o Eu cumpre suas promessas a despeito das mudanças pelas quais pode ter passado em seu caráter), o cumprimento da promessa impõe um intervalo de sentido de ordem temporal que é justamente - lugar onde a identidade narrativa se instala para expressar a permanência no tempo da identidade (RICOEUR, 2014, p. 124-126).

A dialética entre mesmidade e ipseidade assim exposta em sua dimensão temporal é revelada por Ricoeur (2014) como a dialética da personagem - o modo como o enredo da narrativa transpõe a teoria da ação para o reino das personagens narrativas. Os termos desta dialética referem-se ao que o autor chama, voltando a Aristóteles, de concordância e de discordância na urdidura do enredo da narrativa. Concordância significa o princípio de ordem, de organização, na narrativa. Discordância designa os acontecimentos que provocam mudanças no enredo, transformando-o (RICOEUR, 2014, p. 147). A personagem, de um lado, extrai singularidade da unidade de sua vida ordenada como uma totalidade temporal também singular - é o lado da concordância. Por outro, a personagem vê a totalidade temporal da sua identidade ameaçada pela eventualidade de acontecimentos imprevisíveis - é o lado da discordância. A síntese resultante deste conflito dialético é a ascensão da identidade pessoal aos domínios da narratividade, em que o acontecimento contingente contribui para a articulação retroativa de uma história da vida da personagem, que se iguala a sua identidade (RICOEUR, 2014, p. 154-159). Portanto, a identidade narrativa do sujeito personagem, um coroamento da dialética entre mesmidade e ipseidade, faz coincidir este sujeito (que é personagem e coautor) com suas experiências, de modo que, finalmente,

A narrativa constrói a identidade da personagem, que pode ser chamada de sua identidade narrativa, construindo a identidade da história narrada. É a identidade da história que faz a identidade da personagem. (RICOEUR, 2014, p. 155).

Se a identidade narrativa é uma alternativa entre o sujeito moderno e a ausência completa de sujeito, ela coloca o eu do sujeito em relação dialética com o outro e o mundo. E é na relação com o outro e com o mundo que o gênero dos sujeitos se constrói ao longo de suas ações. $\bigcirc$ gênero, tal qual o sujeito agora, não existe desde antes, ele passa a existir contingencialmente à linguagem em que é produzido.

A teoria da identidade de gênero conforme foi elaborada por autoras feministas 
pós-estruturalistas, como Judith Butler, foi uma reação ao que foi reconhecido como um peso opressivo do sujeito moderno, cuja característica substancial (o ser uma coisa pensante) foi revista como mais uma estratégia de universalização do masculino e do afastamento do feminino - o feminino seria o Outro do qual este sujeito (nunca uma sujeita) se afasta radicalmente. Pensar a construção do gênero juntamente a do sujeito é já uma forma de começar a desatar esta armadilha, como propõe Butler (2012, p. 37):

Seria errado supor que a discussão sobre a "identidade" deva ser anterior à discussão sobre identidade de gênero, pela simples razão de que as "pessoas" só se tornam inteligiveis ao adquirir seu gênero em conformidade com padrões reconhecíveis de inteligibilidade de gênero.

Para as autoras do feminismo pós-estruturalista, das quais Butler (2012) é eminente representante, o gênero não é uma substância (um substantivo), tampouco é um conjunto de qualidades (adjetivos do sujeito) flutuantes. $O$ gênero, ao se fazer identidade, tem um efeito substantivo produzido e imposto por práticas culturais e regimes discursivos reguladores da sua inteligibilidade entendida como o manter, pelo gênero, relações de coerência e continuidade entre sexo, gênero, prática sexual e desejo. Dentro destes limites, a identidade de gênero inteligivel é performatizada como substância (BUTLER, 2012, p. 37-48).

Assim, a identidade de gênero que se faz de modo performativo é também, como a identidade narrativa, uma crítica ao sujeito moderno. A necessidade de padrões culturais de inteligibilidade como conformadores do gênero dialoga com as noções de contexto e de enredo como formadores da identidade narrativa.

Diante disso, o cruzamento com o conceito de identidade narrativa aparece como uma possibilidade de redimensionamento da performatividade de gênero de um sujeito que se constrói na narrativa. $O$ sujeito generificado de Butler (2012), constituído pela exclusão e pela diferenciação, que esconde sua origem excludente e cria, por meio deste subterfúgio, a ilusão de sua autonomia, mesmo sendo um ataque radical ao sujeito universal e autônomo da modernidade, não precisa significar a morte do último. Antes, apresenta uma via, que, propomos com este artigo, é, ao mesmo tempo, narrativa e performática, para que a questão do sujeito não recaia na fragmentação e no relativismo estéreis.

Feito este trajeto de encruzilhadas entre a formação da subjetividade com marcas de gênero pela performatividade dos atos e pela narrativa, chega-se ao ponto do texto em que se deveria oferecer conclusões ao leitor. Todavia, concluir também significa fechar o pensamento, declarar um ponto de chegada conceitual ou um fim. Assim, ao invés de concluir o trajeto, que, ao contrário, apenas se inicia, extravasando os limites deste texto, oferecer-se-á indicativos de novos 
caminhos para a identidade cujas marcas de gênero se dão narrativamente.

Entre estas trilhas, a dimensão ética das identidades de gênero aparece como um campo a ser explorado. Pensar a narratividade da performatividade de gênero abre a identidade de gênero para as discussões das éticas da ação, seguindo a proposta de mediação estabelecida pelo narrar entre o descrever (teoria da ação) e o prescrever (ética) feita por Ricoeur (2014). Aqui, a estilização da existência pelo cuidado de si como forma de subversão das identidades de gênero aparece como um possível fio condutor de uma narrativa de si cuja finalidade é uma boa vida ou um bom modo de viver. $O$ que abre uma interrogação com que talvez - lado religioso de Ricoeur teria se espantado; seriam justamente aquelas vidas que, ao contestarem a matriz heterossexual que dá inteligibilidade às práticas culturais e aos regimes discursivos que formam identidades de gênero estáveis, se põe à margem dos padrões morais da religião, do Estado e mesmo do senso comum sobre o gênero as que mais cuidadosamente estilizam suas existências? Seriam estas personagens culturais marginais (as dragqueens, as e os transexuais, as pessoas intesexo e queer entre muitas outras) as que melhor constroem uma boa identidade narrativa?

\section{Referências}

BIRCHAL, Telma de Sousa. O Eu nos Ensaios de Montaigne. Belo Horizonte: Editora UFMG, 2007.

BUTLER, J. Bodies that matter. On the discursive limits of "sex". Londres: Routledge, 1993.

Problemas de Gênero. Feminismo e subversão da identidade. Trad. Renato Aguiar. Rio de Janeiro: Civilização Brasileira, 2012.

DERRIDA, Jacques. Assinatura, acontecimento, contexto. In: DERRIDA, Jacques. Margens da filosofia. Trad. Joaquim Torres Costa, Antônio Magalhães; Revisão técnica: Constança Marcondes Cesar. Campinas, SP: Papirus, 1991, p. 349-373.

DESCARTES. Discurso do método. Meditações. Objeções e respostas. As paixões da alma. Cartas. Trad. J. Guinsburg, Bento Prado Júnior. São Paulo: Abril Cultural, 1973.

FOUCAULT, M. O nascimento da clínica. Trad. Roberto Machado. Rio de Janeiro: Forense-Universitária, 1977.

História da Sexualidade I. A vontade de saber. Trad. Pedro Tamen. 
Lisboa: Antropos, Relógios d'água, 1977.

. Nietzsche, a genealogia e a história. In: Microfísica do poder. Trad. Roberto Machado. Rio de Janeiro: Edições Graal, 1979, p. 15-37.

História da Sexualidade II. O Uso dos prazeres. Trad. Maria Thereza da Costa Albuquerque. Rio de Janeiro: Edições Graal, 1984.

A hermenêutica do sujeito. Curso dado no Collège de France (19811982). Trad. Márcio Alves da Fonseca, Salma TannusMuchail. São Paulo: Editora WMF Martins Fontes, 2010.

Vigiar e Punir. Nascimento da prisão. 39. Ed. Trad. Raquel Ramalhete. Petrópolis, RJ: Vozes, 2011.

Ditos e Escritos V. Ética, sexualidade, política. 3.ed. Organização, seleção de textos e revisão técnica Manoel de Barros da Motta. Tradução Elisa Monteiro, Inês Autran Dourado Barbosa. Rio de Janeiro: Forense Universitária, 2012. (Ditos e escritos;5).

História da loucura. Na Idade Clássica. Trad. José Teixeira Coelho Neto. São Paulo: Perspectiva, 2012.

MACINTYRE, A. Depois da virtude. Um estudo em teoria moral. Trad. Jussara Simões; revisão técnica Helder Buenos Aires de Carvalho. Bauru, SP: EDUSC, 2001.

NIETZSCHE, Friedrich. Genealogia da moral. Tradução, notas e posfácio Paulo César de Souza. São Paulo: Companhia das Letras, 2008.

RICOEUR, Paul. O si-mesmo como outro. Trad. Ivone C. Benedetti. São Paulo: Editora WMF Martins Fontes, 2014.

SALIH, Sara. Judith Butler e a teoria queer. Tradução e notas Guacira Lopes Louro. Belo Horizonte: Autêntica editora, 2012.

SMITH, Bonnie G. The gender of history. Men, women, and historical practice. Cambridge, Massachusetts: Harvard University Press, 1998.

TAYLOR, Charles. Sources of the self. The making of the modern identity. New York, NY: Universityof Cambridge Press, 1989.

VELLEMAN, J. David. Self to self. Sellected essays. New York, NY: Cambridge University Press, 2006.

VEYNE, P. Foucault. O pensamento, a pessoa. Lisboa: Edições Textos \& Grafia, 2009. 
Recebido em junho de 2018

Aprovado em setembro de 2018 